Síntese - Rev. de Filosofia

v. 37 N. 119 (2010): 371-381

\title{
JUSTIÇA, ALTERIDADE E VOLÊNCIA \\ UMA ABORDAGEM À LUZ DA MORAL PURA KANTIANA
}

\author{
(Justice, Alterity and Violence, an approach in the light of Kant's pure \\ morals)
}

Edgard José Jorge Filho *

Resumo: Apresenta-se uma abordagem, baseada na filosofia kantiana, da questão da relação entre Justiça, Alteridade e Violência. Entende-se a questão da Alteridade como a da devida conciliação da essencial igualdade dos homens com as diferenças de seus modos de vida, o problema da Violência como o da coação injusta ou como o da aprovação ou desaprovação indevidas e a questão da Justiça como a da legalidade ou moralidade. Propõe-se uma forma de viabilizar tal conciliação. A hipótese é que aquela abordagem e essa proposta seriam possíveis em conformidade com os critérios do Direito Puro e da Ética Pura kantianos, pois estes possibilitam uma avaliação racional, embora consideravelmente abstrata, das ações e fins implicados naquela relação.

Palavras-chave: Justiça, Alteridade, Violência, Direito, Ética, Kant

Abstract: Our approach, based on Kant's practical philosophy, deals with the question of the relationship between Alterity, Justice and Violence. The issue of Alterity is understood as that of duly conciliating the essential equality of men with their different ways of life; the problem of Violence is comprehended as that of unjust coercion or undue approval or disapproval, and the question of Justice as that of legality or morality. We propose a way of making that

\footnotetext{
* Doutor em Filosofia pela Universidade Federal do Rio de Janeiro, Professor Assistente da Pontifícia Universidade Católica do Rio de Janeiro. Artigo submetido a avaliação no dia 31/07/2010 e aprovado para publicação no dia 15/09/2010.
} 
conciliation feasible. The hypothesis is that our approach and proposal would be possible according to Kant's criteria of Pure Right and Pure Ethics, for these allow for a rational, though considerably abstract, appraisal of the actions and ends implied in the above mentioned relationship.

Keywords: Justice, Alterity, Violence, Right, Ethics, Kant

$\mathrm{E}$ ste ensaio apresenta uma abordagem, baseada na filosofia prática de Kant, da questão da relação entre Justiça, Alteridade e Violência. Aqui se poderão encontrar, talvez, indicações teóricas para um possível diálogo com perspectivas teóricas mais propriamente contemporâneas de tratamento dessa questão.

Pressupõe-se, inicialmente, que a questão da Alteridade, do ser-outro, pode entender-se como a da possível e devida conciliação da essencial igualdade dos homens com a multiplicação das diferenças de seus modos de vida. $\mathrm{O}$ problema da Violência, por sua vez, é aqui entendido, de um lado, como o do emprego injusto da força física (coação injusta), e, de outro lado, como o da aprovação ou reprovação indevidas, (louvor ou censura indevidos). Já a questão da Justiça, embora se coloque mais propriamente como uma questão jurídica, da esfera do Direito, também pode ser colocada do ponto de vista da Ética, se entendida a Justiça num sentido lato, como envolvendo não apenas a legalidade, mas também a moralidade das ações.

De que modo seria possível, segundo o enfoque adotado aqui, baseado na filosofia prática de Kant, abordar a questão da relação entre Justiça, Alteridade e Violência e, assim, propor uma forma de conciliar a promoção da diversidade e a multiplicação das diferenças com a preservação da essencial igualdade dos homens, como seres livres e racionais, possuidores de dignidade, evitando desta forma a violência?

A hipótese é a seguinte: aquela abordagem e essa proposta seriam possíveis em conformidade com os critérios do Direito Puro e da Ética Pura concebidos por Kant, porém seriam consideravelmente abstratas. Pois, essas Doutrinas kantianas possibilitam uma avaliação, com base num critério racional, a priori, das ações e dos fins implicados na relação entre Justiça, Alteridade e Violência; tal avaliação, porém, não faz jus à complexidade concreta das intenções e relações interpessoais aí envolvidas.

Na primeira parte do ensaio será apresentada a distinção entre a Ética Pura e o Direito Puro, como divisões da Metafísica dos Costumes, e considerada sob a ótica do Direito Puro a questão da relação entre Justiça, Alteridade e Violência. Na segunda parte, essa questão será recolocada e considerada do ponto de vista da Ética Pura. 
O Direito Puro e a Ética Pura constituem as duas divisões da Moral Pura, ou Metafísica dos Costumes, kantiana. Esta é a parte racional, pura, da Filosofia Moral kantiana e tem como objetos a vontade, o livre-arbítrio e suas leis da liberdade. ${ }^{1}$ O Direito Puro e a Ética Pura são doutrinas cujos princípios são simplesmente a priori, universais e necessários, e a diferença entre eles consiste na distinção das suas legislações. Antes de se abordar esta diferença de legislações, alguns esclarecimentos preliminares se fazem necessários.

A faculdade de desejar em geral é definida como a faculdade de ser, mediante suas representações, causa dos objetos dessas representações. O livre-arbítrio (freie Willkür) é definido por Kant como a faculdade de desejar mediante representações conceituais, cujo motivo, ou fundamento de determinação (Bestimmungsgrund), encontra-se em si mesma e não no objeto e que é acompanhada da consciência do poder de realizar os objetos dessas representações. O voto (Wunsch), por sua vez, diferencia-se do livre-arbítrio por não ser acompanhado dessa consciência. ${ }^{2}$ A vontade (Wille), por sua vez, é essa faculdade de desejar mediante conceitos, considerada não tanto em relação às ações, mas aos motivos do livre-arbítrio à ação e enquanto pode determiná-lo; em outros termos, é a razão prática.

Toda legislação da liberdade possui dois elementos: uma lei e um móbil (Triebfeder). Uma lei da liberdade é uma regra objetiva da vontade, com a forma da universalidade, e o caráter de uma obrigação, cujo cumprimento é um dever; e o móbil é um incentivo para o cumprimento da lei, que liga subjetivamente a lei ao princípio subjetivo de determinação do livrearbítrio, isto é, à máxima. Os móbiles das duas legislações são distintos: o da legislação ética, interior, é o respeito à lei, ou a própria Ideia do dever; o móbil suficiente da legislação jurídica, exterior, liga-se à coação exterior e é, em última instância, o amor-de-si humano. ${ }^{3}$ Ética Pura e Direito Puro constituem, nesta medida, duas legislações distintas, a primeira interior, legislando especificamente para o uso interior da liberdade, na adoção de máximas e fins, a segunda exterior, legislando somente para o uso externo da liberdade, isto é, para a interação exterior dos livres-arbítrios. Se a legislação é exterior, os deveres correspondentes são jurídicos; se é interior, eles são éticos.

\footnotetext{
${ }^{1}$ Cf. KANT, I., Metaphysik der Sitten, in Kant'sgesammelte Schriften, Hrsg.: Bd. 1-22 Preussische Akademie der Wissenschaften, Bd. 23 Deutsche Akademie der Wissenschaften zu Berlin, ab Bd. 24 Akademie der Wissenschaften zu Göttingen, Berlin, 1900ff., vol. 6, p. 216; Grundlegung zur Metaphysik der Sitten, in Kant'sgesammelte Schriften, vol. 4, pp. 387, 390. Haverá, doravante, referência a esta edição pela abreviação AkademieAusgabe.

${ }^{2}$ Cf. KANT, I., Metaphysik der Sitten, in Akademie-Ausgabe, vol. 6, p. 211.

${ }^{3}$ Cf. KANT, I., Metaphysik der Sitten, in Akademie-Ausgabe, vol. 6, pp. 218, 219.
} 
Considere-se, então, o ponto de vista do Direito Puro, ou racional. De acordo com Kant, a Doutrina do Direito delimita o seu objeto da seguinte maneira: primeiramente, ela se ocupa somente com as relações práticas e externas entre pessoas, na medida em que suas ações se influenciam reciprocamente; em segundo lugar, ela considera apenas as relações entre os livres-arbítrios, não a relação entre o livre-arbítrio de um e o mero voto, ou desejo impotente, de outro; finalmente, faz abstração da matéria, ou do fim das ações, levando em conta apenas a sua forma, isto é, o modo de relação das ações exteriores dos livres-arbítrios. ${ }^{4}$ Nesta medida, a legislação jurídica está concernida apenas com a legalidade das ações, a simples conformidade delas às leis jurídicas, sejam quais forem as intenções dos agentes, mas não com a sua moralidade, pois esta diz respeito às intenções, à adoção de máximas e fins. Cabe à legislação ética estabelecer as condições para a moralidade das ações.

Àquela delimitação do objeto do Direito corresponde a definição deste: “É o conjunto das condições sob as quais o livre-arbítrio de um pode consistir com o livre-arbítrio de outro segundo uma lei universal da liberdade". ${ }^{5}$ Note-se que o Direito está concernido com a forma da coexistência exterior de uma pluralidade de livres-arbítrios. Nesta medida, ele nada determina positivamente quanto às matérias, ou fins, das ações exteriores dos livresarbítrios; contudo, estabelece uma condição limitadora: a exigência de que a realização dos fins particulares dessas ações permitam a coexistência dos livres-arbítrios segundo uma lei universal.

Direito e Justiça se identificam em Kant; assim é que a Doutrina do Direito é também denominada Metafísica da Justiça. Daí a definição da ação justa: "justa é a ação que permite, ou cuja máxima permite, a coexistência dos livres-arbítrios segundo uma lei universal". ${ }^{6}$ A ação que se opuser a esta coexistência segundo uma lei universal será injusta. Ou seja, a ação injusta é a que impede essa coexistência dos livres-arbítrios segundo uma lei universal.

O Direito possui uma característica distintiva, peculiar: há uma conexão essencial dele com a faculdade, ou autoridade (Befugnis), de coagir.7 Pois, para permitir a coexistência dos livres-arbítrios segundo uma lei universal, é preciso que o Direito possa opor uma resistência à ação que impede essa coexistência, isto é, ele tem que poder impedir aquelas ações exteriores que impedem a coexistência das liberdades segundo uma lei universal. Em outros termos, ele tem que poder impedir as ações injustas, permitindo somente assim a coexistência dos livres-arbítrios segundo uma lei univer-

${ }^{4}$ Cf. KANT, I., Metaphysik der Sitten, in Akademie-Ausgabe, vol. 6, p. 230.

${ }^{5}$ KANT, I., Metaphysik der Sitten, in Akademie-Ausgabe, vol. 6, p. 230.

${ }^{6}$ KANT, I., Metaphysik der Sitten, in Akademie-Ausgabe, vol. 6, p. 230.

${ }^{7}$ Cf. KANT, Metaphysik der Sitten, in Akademie-Ausgabe, vol. 6, p. 231. 
sal. Este poder de impedir as ações exteriores injustas é a faculdade de coagir, essencial ao Direito. Note-se que não se trata de um poder de coação arbitrário, pois este configuraria a injustiça, mas sim de uma faculdade de coagir segundo uma lei universal, elemento essencial do Direito, ou da Justiça.

Essa faculdade de coagir é, pois, característica essencial do Direito, tanto na esfera do Direito Privado quanto na do Direito Público. Na primeira, consiste numa faculdade de coação recíproca universal no estado de natureza, onde, devido à dispersão e fraqueza da coação, o Direito é privado de garantias. Na segunda, com a concentração da faculdade de coagir numa instância publicamente autorizada e com a sua submissão a uma lei comum, o Direito recebe sua garantia.

Ora, já se dispõe de elementos para um tratamento preliminar da questão proposta. Considerando a existência num estado de direito público, como se poderia conciliar a essencial igualdade dos homens enquanto seres livres e racionais com a diversificação e a multiplicação das diferenças dos fins particulares? Convencionando-se chamar de violenta a ação injusta, mas não simplesmente a coação pelo emprego, em última instância, da força física, pois tal coação poderia, em muitos casos, impedir a injustiça, então pode-se fazer a seguinte consideração: as pessoas, individual ou coletivamente, poderiam eleger e realizar livremente os seus fins particulares, não determinados pelo Direito Puro (concernido não com a matéria, mas tão-somente com a forma das ações exteriores), sob uma condição limitativa: que essa realização dos fins particulares não impeça a coexistência dos livres-arbítrios segundo uma lei universal. Tal condição exige o exercício justo da liberdade dos livres-arbítrios, sem conferir privilégios, porquanto submete todos a uma lei universal. O Direito Puro Público pressupõe e fomenta a essencial igualdade dos homens, enquanto seres livres e racionais, na medida em que garante a coexistência de todos os livres-arbítrios segundo uma lei universal: ao mesmo tempo permite, sob esta condição, a livre escolha e realização dos fins particulares, não tolhendo a diversificação, antes, possibilitando-a para todos, sem exceção.

Assim, a coação essencial ao Direito Puro Público não constitui uma violência nem tolhe a diversificação, antes, é a garantia para a justa conciliação da essencial igualdade de seres livres e racionais com a livre realização da diversidade de seus fins e propósitos.

Advirta-se, porém, que essas considerações se fazem do ponto de vista do Direito Puro, concernido apenas com a forma das relações entre os livresarbítrios, abstração feita das matérias das ações. Como o Direito Puro Público é apenas uma Ideia, um conceito puro da razão, da qual, entretanto, o Direito Positivo deveria se aproximar, ele não fornece a medida concreta para aquela conciliação. Isto seria da competência das constituições efetivamente existentes, empiricamente cognoscíveis e que em suas legislações 
positivas incidem na determinação de matérias das ações exteriores, enquanto que a determinação da simples forma destas cabe somente ao Direito Puro. A conciliação real da igualdade dos homens com a diversificação dos seus fins, num contexto de justiça e não-violência, é problema de enorme complexidade e dificuldade, pois exige a consideração de fatores históricos, sociais, econômicos e culturais em geral, que condicionam a escolha dos diversos fins e nela influenciam. $\mathrm{O}$ aporte valioso do Direito Puro kantiano consiste em fornecer uma Ideia e um princípio regulador universal, para o equacionamento jurídico da relação entre Justiça, coação, igualdade essencial e diversidade dos fins.

Uma outra questão, que recoloca sob um outro ângulo o problema da Alteridade em relação com a Justiça e a Violência, deve ser considerada. Trata-se da questão do louvor ou da censura, da aprovação ou reprovação de ações, hábitos ou costumes. Mais precisamente, haveria algum critério racional segundo o qual se pudesse julgar o louvor ou a censura como devidos (eticamente "justos") ou como indevidos, e neste último caso como "violentos"?

Considerem-se, particularmente, as ações permitidas pelo Direito Puro Público, sobre cujos autores não devesse recair nenhuma coação exterior justa, com o emprego da força física pelo poder executivo do Estado. A regularidade de tais ações não injustas poderia configurar certos hábitos ou costumes juridicamente lícitos. Mas, não poderiam recair sobre elas juízos de louvor ou de censura? Admitida essa possibilidade, com que critério se contaria para julgar se o louvor ou a censura são devidos ou não? Aqui entendem-se por louvor ou censura devidos os que atendem a um critério supostamente universal e necessário, fundado na razão, e não em convenções ou tradições. Como o sistema da Moral Pura, ou Moral Racional, de Kant - a Metafísica dos Costumes - divide-se em Direito Puro e Ética Pura, cabe examinar se, abstraindo-se da pedra de toque do Direito Puro, adequada para a avaliação da justiça ou injustiça das ações e condutas, a Ética Pura poderia fornecer um critério racional para avaliar os juízos de louvor ou censura.

A Ética Pura, a outra divisão da Moral Pura, ou Metafísica dos Costumes, é a doutrina do sistema dos fins que são em si mesmos deveres, ou dos deveres de virtude. ${ }^{8}$ Neste sistema articulam-se, com fundamento na humanidade na pessoa de cada um como fim em si, os fins incondicionais

${ }^{8}$ Cf. KANT, I., Metaphysik der Sitten, in Akademie-Ausgabe, vol. 6, pp. 381, 383. 
da felicidade de outrem e da própria perfeição: nestes últimos se resumem os deveres de virtude, aqui entendidos como deveres éticos da pessoa individual. ${ }^{9}$ Vale ressaltar que esses fins-deveres são deveres latos, de realização imprecisamente determinada, à diferença dos deveres jurídicos, que são estritos, de realização precisamente determinada. Por isso, tais deveres éticos, enquanto deveres latos, não possibilitam um julgamento muito preciso. ${ }^{10}$

Como a adoção de máximas e de fins, especialmente dos fins últimos, que não são fins-meios, ou fins intermediários, é assunto de foro interno exclusivamente, sobre o qual a coação externa, jurídica, não possui qualquer eficácia, tal adoção depende somente de incentivos, ou móbiles, internos. Com efeito, a legislação ética é uma legislação interna, em contraposição à legislação jurídica, externa, e o móbil daquela é a Ideia do dever, ou o respeito à lei moral. Se o móbil do livre-arbítrio é a Ideia do dever, a ação é realizada por dever e tem valor moral. Como ensina a Fundamentação da Metafísica dos Costumes, só pode realizar-se por dever uma ação que é conforme ao dever, nunca uma ação contrária ao dever. ${ }^{11}$ A legislação ética ordena que a ação se realize por dever.

A Ética é uma Doutrina da Virtude, porque a adesão a máximas e aos fins que constituem a matéria destas, requer uma força moral da alma, capaz de resistir firme e resolutamente a um forte e injusto adversário (interno) da intenção moral. Tal força e disposição refletida para aderir firme e resolutamente a um sistema de fins da razão prática pura é a virtude. Em outros termos, esta é a disposição firme e refletida para agir por dever. $\mathrm{O}$ vício é a disposição contrária a esta. ${ }^{12}$

Chegando ao ponto: poderia a Ética Pura servir de critério para os juízos de louvor ou censura devidos de hábitos ou costumes não injustos (não ilegais)? Ora, o simples louvor ou censura (desprovidos de coercitividade externa) de hábitos ou costumes, supondo-se a não-injustiça destes (do ponto de vista do Direito Puro), teriam de recair sobre supostos fins particulares, cuja realização reiterada se expressaria nesses mesmos hábitos ou costumes. Se estes satisfazem os limites definidos pelo Direito Puro relativamente à forma das ações, então a avaliação racional dos fins supostamente realizados nesses hábitos ou costumes deveria, presumidamente, ser da alçada de uma outra doutrina, concernida com a questão dos fins. A Ética Pura, concernida com o sistema dos fins que são em si mesmos deveres, seria essa doutrina. Cabe explorar esta hipótese.

\footnotetext{
${ }^{9}$ Cf. KANT, I., Metaphysik der Sitten, in Akademie-Ausgabe, vol. 6, p. 385.

${ }^{10}$ Cf. KANT, I., Metaphysik der Sitten, in Akademie-Ausgabe, vol. 6, p. 390.

${ }^{11}$ Cf. KANT, I., Grundlegung zur Metaphysik der Sitten, in Akademie-Ausgabe, p. 397.

${ }^{12}$ Cf. KANT, I., Metaphysik der Sitten, in Akademie-Ausgabe, vol. 6, pp. 380, 384.
} 
Considere-se a questão do autojuízo. Supondo-se que a pessoa identifique acertadamente os seus próprios fins, pode-se admitir que, conforme o critério dos fins a servir-lhe de padrão de juízo, haveria uma autoavaliação que se poderia considerar correta ou incorreta. Se tal critério é o racional, isto é, o do sistema objetivo, a priori, dos fins que são deveres, constituído pela Ética Pura, a auto-avaliação à sua luz seria correta; se, contudo, o sistema-padrão de fins for empírico, erigido arbitrariamente ou segundo uma ótica eudaimonista, a autoavaliação seria incorreta. ${ }^{13}$ Dando um passo além, chamar-se-ia essa avaliação de "violenta", embora comporte apenas louvor ou censura indevidos, mas não coação injusta pela força física.

Um autojuízo ético efetivamente correto depende, porém, não apenas da justeza do critério, mas também da correta identificação dos próprios fins. Ora, parece que somente a própria pessoa pode perscrutar os seus fins, envoltos em obscuridade, recorrendo a esse juiz interior que é a consciência moral (Gewissen), portanto, somente ela poderia reconhecer se age por dever ou não. Porém, há no tocante a isso uma certa assimetria. Se é extremamente difícil a pessoa julgar, de modo correto e seguro, que age por dever, em virtude do poder da autoilusão, capaz de disfarçar a supremacia do princípio imoral, é mais fácil e certo julgar a própria ação ou conduta como imoral ou desprovida de valor moral, caso se evidencie sua contrariedade ao dever, pois, então, não se poderia realizar por dever. Em outras palavras, a autocensura seria mais certa, justificada e fácil, do que a autoaprovação.

E quanto à possibilidade de um juízo ético justificado e correto das ações ou condutas de outrem, particularmente dos hábitos alheios ou costumes? A Ética Pura forneceria o critério racional, a priori, do sistema dos fins que são em si mesmos deveres, adequado para todo juízo ético universalmente válido. Mas, como o juízo ético diz respeito à adoção de máximas e à adesão a fins, e como isso é assunto de foro interno, sendo imperscrutáveis os autênticos fins de outrem, então parece inviável julgar eticamente terceiros. Entretanto, a consideração daquela assimetria já mencionada permite nuancear esta conclusão. Pois, se outras pessoas agem reiteradamente contra o dever, isto permite justificadamente negar que ajam por dever e recusar valor moral a suas ações. Indo mais além, julgar-se-ia imoral, contrário ao dever ético, sua conduta. Seriam, portanto, justificados os juízos éticos de censura de hábitos alheios ou costumes reconhecidamente contrários ao dever. Porém, no tocante aos juízos éticos de aprovação de hábitos alheios ou costumes, haveria uma impossibilidade. Pois, é correto e justificado apenas o louvor ético de ações realizadas por dever, com a adesão a fins que são em si mesmos deveres; ora, como os fins eleitos por terceiros

${ }^{13}$ Cf. KANT, I., Kritik der praktischen Vernunft, in Akademie-Ausgabe, vol. 5, pp. 21, $22,27$. 
são ainda mais insondáveis do que os meus próprios fins, obscuros para minha consciência moral, conclui-se pela impossibilidade de um juízo ético seguro e justificado de aprovação de terceiros.

Talvez o critério para o juízo ético definido pela Ética Pura possa ser utilizado para um certo juízo ético "fraco" de aprovação de hábitos alheios ou costumes. Admitindo-se que estes consistam na reiteração de ações em que se realizem supostos fins particulares recorrentes, então, caso se avaliem favoravelmente esses supostos fins, comparando-os com o sistema de fins estabelecido pela Ética Pura, podem-se aprovar os hábitos alheios ou costumes em que tais fins presumidamente se realizam. É claro que aqui se julgam objetivamente os fins apenas supostamente realizados em hábitos alheios ou costumes, mas, a rigor, não é possível um juízo ético aprobatório de outras pessoas, pois sua adesão a fins é imperscrutável ao juiz externo. O que se pode é presumir, com alguma probabilidade, que essas pessoas engajadas na prática de hábitos ou costumes possam ter aderido aos fins, pelo menos aos fins-meios, supostamente realizados neles. Tudo permanece, porém, no âmbito da incerteza e da simples plausibilidade. Com base nesta, é possível um juízo ético "fraco" de aprovação de hábitos alheios ou costumes. Fraco porque calcado na incerteza inevitável quanto à efetiva e firme adesão de outras pessoas aos fins da moralidade.

A justificação da posição privilegiada dos juízos éticos de censura em relação aos de aprovação permite compreender o juízo ético kantiano tão desfavorável a todos os homens. Ao recorrer à experiência e à história, Kant reconhece a pletora de ações em choque frontal com o dever, cometidas por civilizados, bárbaros ou selvagens, o que justificaria o seu juízo ético tão desfavorável a todos os homens. ${ }^{14}$ Ele reconhece o problema do mal radical da natureza humana. Segundo Kant, há em nós uma propensão ao mal (Hang zum Bösen), não intrínseca à essência humana, mas contingente, contraída por um ato livre originário, atemporal e inexplicável, que se estende a todos os homens sem exceção. ${ }^{15}$ Tal propensão consiste na firme adesão a uma máxima fundamental má, adotada livremente pelo arbítrio humano, da qual derivariam todas as outras máximas, corrompidas pela raiz. Contudo, há distintos graus dessa propensão ao mal: em ordem crescente, a fraqueza, a impureza e a corrupção. ${ }^{16}$ Os homens propensos ao mal no mais alto grau seriam, supostamente, aqueles com maior tendência a agir contrariamente ao dever, jurídico ou ético. Embora haja em nós, por outro lado, uma disposição natural, essencial, ao bem, ela se

${ }^{14}$ Cf. KANT, I., Die Religion innerhalb der Grenzen der blossen Vernunft, in AkademieAusgabe, vol. 6, pp. 32-34.

${ }^{15}$ Cf. KANT, I., Die Religion innerhalb der Grenzen der blossen Vernunft, in AkademieAusgabe, vol. 6, p. 28.

${ }^{16}$ Cf. KANT, I., Die Religion innerhalb der Grenzen der blossen Vernunft, in AkademieAusgabe, vol. 6, p. 29. 
encontra dominada pela propensão ao mal e, conquanto possibilite nossa conversão ao bem, por uma "revolução na maneira de pensar" (Revolution in der Denkungsart), não teria efetivado essa conversão. ${ }^{17}$ Esta dependeria não apenas dos esforços individuais, mas da instituição de uma comunidade ética (Igreja universal e invisível), em que se fomentaria o esforço comunitário em prol da virtude e cujo soberano seria a Inteligência Suprema, ou Deus.

O problema do mal radical traz, porém, uma dificuldade que parece esvaziar a proposta de viabilizar o juízo ético tanto de si próprio quanto de outrem. Se o mal se encontra na raiz dos homens sem exceção, não é forçoso julgar ou pré-julgar todos como maus? Todo interesse adicional pelo juízo ético não seria vão? Não se lograria, com tal pretensão de ainda julgar, somente obscurecer o óbvio? Há pelo menos uma razão para responder negativamente a essas questões: é que a conversão ao bem é um dever incondicional e o cultivo da atenção da consciência moral (juiz interior) aos móbiles da ação é necessário para essa conversão, pois só o homem consciencioso é capaz de rebaixar a autoestima ao confrontá-la com o respeito à lei. De todo modo, foge ao escopo deste ensaio um aprofundamento dessa discussão.

Seja como for, uma vez que o juízo ético em geral toma como critério um sistema objetivo de deveres de virtude, que são deveres latos, imprecisamente determinados, tal juízo não pode, de modo geral, comportar precisão, e por isso parece que se coaduna com a tolerância. Nesta medida, parece que a conduta ética, conforme a virtude, seria compatível com uma considerável diversificação dos fins particulares intermediários, conciliando-a com a exortação ao respeito à humanidade na pessoa de cada um como fim em si e à promoção da felicidade de outrem e da própria perfeição como fins-deveres incondicionais. Por outro lado, a latitude própria dos deveres éticos parece tornar insatisfatório o juízo ético que os toma como critério e requerer um tratamento mais preciso e concreto do problema da conciliação da essencial igualdade dos homens, enquanto livres e racionais, com a diversidade de seus fins particulares (o problema da Alteridade face ao louvor e à censura). Uma ciência empírica, nos moldes da Antropologia Prática sugerida por Kant, poderia determinar as condições psicológicas, sociais e culturais, que devem ser ponderadas com vistas à determinação do grau de força d'alma (virtude) necessário ao cumprimento do dever ético e merecedor de louvor. Pois, em função da intensidade das inclinações, influenciada por tais condições e conhecida empiricamente por aquela ciência, estimar-se-ia o grau de força d'alma

${ }^{17}$ Cf. KANT, I., Die Religion innerhalb der Grenzen der blossen Vernunft, in AkademieAusgabe, vol. 6, pp. 26, 47. 
necessária para dominá-las e cumprir o seu dever. Tal ciência possibilitaria um juízo ético menos lato no caso do autojuízo e também no do juízo ético sobre os hábitos alheios ou costumes.

Assim, a Moral Pura kantiana, dividida em Direito Puro e Ética Pura, parece fornecer um critério racional e elementos heuristicamente valiosos para a investigação da questão em foco, a da relação entre Justiça, Alteridade e Violência. Mas, o aporte do Direito Puro e da Ética Pura para essa investigação é consideravelmente abstrato, porquanto faz-se abstração não apenas do Direito Positivo, estatuído e empiricamente cognoscível, como também de uma doutrina das virtudes empírica, ligada à Antropologia Prática, e da ideia, aventada na obra A Religião dentro dos Limites da simples Razão, de um enfoque comunitário da Ética, concernido com uma legislação ética pública, formadora de uma comunidade ética (Igreja universal e invisível), que possibilitaria a superação do estrito individualismo ético.

\section{Bibliografia:}

GÓMEZ CAFFARENA, J., La coherencia de la filosofía moral kantiana, in Kant después de Kant: en el bicentenario de la Crítica de la Razón Práctica, Madrid, Tecnos, 1989.

GOYARD-FABRE, S., Kant et le problème du Droit, Paris, J. Vrin, 1975.

KERSTING, W., Politics, freedom and order: Kant's political philosophy, in Guyer, P., (ed.) The Cambridge Companion to Kant, Cambridge, Cambridge University Press, 1994.

HÖSSL, D., Recht und Zwangsbefugnis bei Kant, in Kant und die Berliner Aufklärung, Akten des IX Internationalen Kant-Kongresses, Berlin, Walter de Gruyter, 2001, Bd.4.

KANT, I., Gesammelte Schriften, Hrsg.: Bd. 1-22 Preussische Akademie der Wissenschaften, Bd. 23 Deutsche Akademie der Wissenschaften zu Berlin, ab Bd. 24 Akademie der Wissenschaften zu Göttingen, Berlin, 1900ff. (Nas referências bibliográficas adota-se uma referência abreviada a esta edição como AkademieAusgabe.)

Endereço do Autor:

Rua Visconde de Pirajá, 175 apto. 502

22410-001 Rio de Janeiro - RJ

edgard@puc-rio.br 